\title{
Expression profiling of selected microRNA signatures in plasma and tissues of Saudi colorectal cancer patients by qPCR
}

\author{
YAZEED A. AL-SHEIKH ${ }^{1}$, HAZEM K. GHNEIM ${ }^{1}$, KHALIL I. SOFTA ${ }^{1}$, ABDULRAHMAN A. AL-JOBRAN ${ }^{1}$, \\ OMAR AL-OBEED ${ }^{2}$, MANSOOR A.V. MOHAMED ${ }^{2}$, MAHA ABDULLA ${ }^{2}$ and MOURAD A.M. ABOUL-SOUD ${ }^{1}$ \\ ${ }^{1}$ Department of Clinical Laboratory Sciences, College of Applied Medical Sciences, \\ King Saud University, Riyadh $11433 ;{ }^{2}$ Colorectal Research Center, Department of Surgery, \\ College of Medicine, King Saud University, Riyadh 11472, Kingdom of Saudi Arabia
}

Received November 2, 2015; Accepted December 30, 2015

DOI: $10.3892 / \mathrm{ol} .2015 .4068$

\begin{abstract}
MicroRNAs (miRNAs or miRs) have been advocated as potentially robust and highly stable biomarkers of diverse disease conditions including cancer. The primary aim of this study was two-fold: i) to profile the expression levels of selected mature miRNA signature genes, such as $m i R-145, m i R-195, m i R-29$ and $m i R-92$, in a paired-study design of 20 colorectal cancer (CRC) tissues from patients versus adjacent neoplasm-free mucosal tissues employing reverse transcription-quantitative polymerase chain reaction; and ii) to examine their expression level in the plasma of the same CRC patients in relation to the age-matched plasma of healthy controls. Statistically significant $(\mathrm{P}<0.01)$ increases in $m i R$-29 (2.5) and miR-92 (2.6) were observed in CRC tissues compared with adjacent neoplasm-free mucosal tissues. Profiling of CRC plasma samples showed that the expression levels of circulating $m i R-29$ and $m i R-92$ were significantly higher $(\mathrm{P}<0.01)$ than in the age-matched normal plasma. By contrast, miR-145 and miR-195 exhibited significant $(\mathrm{P}<0.05)$ decreases in their mean expression levels in CRC tissue samples in relation to the normal tissues. The mean expression levels of $m i R-145$ and $m i R-195$ were significantly lower $(\mathrm{P}<0.05)$ in $\mathrm{CRC}$ plasma than the healthy controls. Distinct stage-dependent changes in the expression level of the four miRNA gene profiles were observed between stages II and IV plasma of CRC patients relative to the control plasma. Taken together, the results clearly reflect a similar trend for the four miRNA expression levels in tissue and plasma as well as the positive correlation in the levels of miRNAs in tissues and plasma. These findings may be useful to clarify the molecular
\end{abstract}

Correspondence to: Professor Mourad A.M. Aboul-Soud, Department of Clinical Laboratory Sciences, College of Applied Medical Sciences, King Saud University, P.O. Box 10219, Riyadh 11433, Kingdom of Saudi Arabia

E-mail: maboulsoud@ksu.edu.sa

Key words: microRNA, colorectal cancer, plasma, biomarkers, real-time polymerase chain reaction mechanisms underlying colorectal carcinogenesis and to underscore the potential of the investigated miRNAs as novel early diagnostic biomarkers of CRC.

\section{Introduction}

Worldwide, colorectal cancer (CRC) is ranked the third most commonly diagnosed cancer types of in both genders after lung and breast cancers, accounting for almost $10 \%$ of the cancer mortalities each year. Approximately 1.4 million new cases are diagnosed annually with CRC of which there is an estimated mortality rate of $50 \%$ (1). In the year 2005, the population of the Kingdom of Saudi Arabia (KSA) was estimated at 16,945,484, comprising mostly of native Saudis (62\%). In that same year, the Saudi Cancer Registry reported that CRC was the second most common malignancy among Saudis for all ages (10.3\%) and the number one malignancy in males $(11.8 \%)(2,3)$. Additionally, between 1994 and 2003 age-standardized rates for CRC in KSA almost doubled (2). Between 2001 and 2003, while the annual percent change (APC) of CRC incidence in Saudi females exhibited an insignificant increase of $6 \%$, a profoundly rising incidence among Saudi males was observed, with an APC of $20.5 \%$ (4). It has been predicted that by the year 2030, the CRC incidence in KSA may increase four-fold in the two genders (2). This suggests a foreseeable increase in cancer burden mainly attributed to population growth, adoption of unhealthy life styles and its associated risk factors and aging of the population.

Early diagnosis and treatment of CRC positively correlates with higher patient survival rates (5). In the U.S., for example, the 5-year survival rate is as high as $93.2 \%$ for stage I as compared to only $8.1 \%$ for stage IV (5). Consequently, early diagnosis is a vital goal for any healthcare system to achieve a reliable treatment and successful clinical outcome of CRC patients. Several clinical tests are currently employed for CRC screening, including fecal occult blood tests (FOBT), radiologic tests, colonoscopy and stool DNA test. However, none of these approaches have been regarded as the method of choice due to their invasiveness, low sensitivity or high cost $(6,7)$. Thus, it is fundamentally important to search for novel, non-invasive, specific and sensitive biomarkers for the early diagnosis of CRC. 
Recently, microRNAs (miRNAs or miRs), which represent a newly-discovered class of short (19-25 nucleotides) non-coding RNAs, have acquired considerable interest due the roles they play in a variety of cell processes including development, cell cycle progression, cell differentiation, proliferation and apoptosis (8). Bioinformatics and cloning studies have indicated that miRNAs may post-transcriptionally regulate almost $60 \%$ of all human genes and control hundreds of cognate gene targets through their oncogenic or tumor-suppressive activity (9). Aberrant miRNA expressions have been associated with several types of hematological and solid malignant tumors $(10,11)$ including CRC (12-17), highlighting their potential for diagnostic and prognostic applications, and classification of human malignancies $(18,19)$. While the discovery of malignancy-linked RNAs in plasma/serum were first described almost 10 years ago (20), scientific reports on the existence of miRNAs in body fluids such as blood plasma/serum, saliva, urine and semen of cancer patients have only been presented more recently (21-24). Notably, various studies have recently confirmed the potential utility of circulating miRNAs as stable biomarkers for the multi-stage process of carcinogenesis in solid tumors and several other malignancies $(21,23)$.

The investigation of cancer-specific circulating miRNA biomarkers is an emerging and promising field of research. Thus, we aimed in the current study to conduct targeted transcriptional profiling of a panel of four mature miRNA signatures (miR-145, miR-195, miR-29 and miR-92) in the plasma and colorectal tissues of Saudi CRC patients in relation to healthy controls to assess their potential diagnostic value using reverse transcription-quantitative polymerase chain reaction (RT-qPCR). These miRNA genes were particularly selected based on a comprehensive review of relevant literatures and previously published data on CRC $(15,22,25-28)$. In addition, the association between the aberrant expression of these circulating miRNA gene profiles and CRC clinical stages was also evaluated.

\section{Materials and methods}

Patients. The subjects recruited in this study (CRC patients, $\mathrm{n}=20$; healthy neoplasm-free controls, $\mathrm{n}=20$ ) were subjected to rigorous eligibility criteria for the selection (Table I). Patients were excluded if they had been undergoing chemotherapy or radiotherapy prior to blood sampling, or clinically diagnosed with familial adenomatous polyposis or hereditary non-polyposis CRC. The tumor-node-metastasis classification system accepted by the Union for International Cancer Control (29) has been employed for staging of malignant tumors. Signed written and informed consent forms were collected from all the subjects participating in this study for the use of their blood and tissue samples. Research protocols conducted in this project were approved by the Institutional Medical Ethics Review board at the College of Applied Medical Sciences Affiliated to King Saud University (Riyadh, Kingdom of Saudi Arabia). All samples were obtained from the Saudi CRC Biobank at King Khalid University Hospital.

Tissue isolation and RNA extraction. Paired fresh CRC tissue specimens and their adjacent non-cancerous normal mucosa were collected from 20 patients who underwent
Table I. Eligibility criteria for the selection and exclusion of study subjects.

Clinicopathological characteristics

\section{General inclusion criteria}

1 . Age $\geq 18$ years and $\leq 80$ years

2. Not currently residing in an institution, such as a nursing home or shelter

3. Not severely ill in the intensive care unit

4. With the capability to give informed consent

5. Encountered between September 2013 and March 2015

Healthy individuals (plasma control group)

1. Underwent the medical check-up in King Khalid University Hospital

2. Asymptomatic and apparently healthy without a previous history of cancer

3. Confirmed healthy condition without malignancy in the physical examinations

4. No system infection (lung, gastrointestinal or urinary tract)

Colorectal cancer patients (CRC group)

1. Underwent colonoscopy biopsy and colorectal surgical resections

2. Diagnosed by 2 experienced pathologists

4. No pre-operative chemotherapy and radiotherapy

surgical resection of tumors by surgeons and subsequently examined by pathologists. The CRC tissues were histologically confirmed to be an adenocarcinoma of the colon. Tissue specimens were collected in RNAlater ${ }^{\circledR}$ RNA Stabilization Reagent (Qiagen, Hilden, Germany) tubes, snap-frozen in liquid nitrogen, and stored at $-80^{\circ} \mathrm{C}$ until further analysis. Total RNA including miRNAs was extracted from 50-100 mg of cryo-preserved tissues by use of TRIzol ${ }^{\circledR}$ reagent (Invitrogen Life Technologies, Carlsbad, CA, USA) as described in the manufacturer's protocol. In order to maximize RNA yield, a homogenization step was carried out by use of a TissueLyser LT with 5-mm stainless-steel beads (Qiagen).

Plasma preparation and circulating RNA extraction. Blood was drawn from the 20 CRC patients recruited in this study as well as 20 age-matched neoplasm-free healthy subjects. The cancer-free status of blood-donating healthy control subjects was confirmed a priori based on their negative health examination results including: blood test, chest X-ray, abdominal ultrasound examination, FOBT, rectal examination, computed tomography scan and colonoscopy. None of the controls had been previously diagnosed with any types of malignancy. Peripheral whole blood $(8-10 \mathrm{ml})$ was collected from each individual into BD Vacutainer ${ }^{\circledR}$ blood collection tubes (BD Biosciences, Franklin Lakes, NJ, USA) (EDTA spray-coated). Plasma was fractionated from whole blood samples according to the procedure described by Duttagupta et al (30). Freshly drawn whole blood was processed for plasma fractionation and the obtained plasma was frozen at $-80^{\circ} \mathrm{C}$ within $4 \mathrm{~h}$ from blood draw. The plasma samples were spectrophotometri- 
cally analyzed to be free from haemoglobin (31). Hemolyzed plasma samples were excluded from further analysis. Whole blood was centrifuged at $1,700 \mathrm{x}$ g for $10 \mathrm{~min}$. The obtained cloudy supernatant was transferred to a fresh tub and centrifuged at 2,000 x g for $10 \mathrm{~min}$. Subsequently, the obtained supernatant was centrifuged at $12,000 \mathrm{x} \mathrm{g}$ for $10 \mathrm{~min}$ to pellet any remaining cellular debris. Circulating RNA extraction was essentially conducted on $1 \mathrm{ml}$ plasma volume using the Plasma/Serum Circulating and Exosomal RNA Purification kit (Slurry Format; Norgen Biotek Corp., Thorold, ON, Canada) following the manufacturer's instructions. The resulting eluate was subjected to an additional concentration step by the use of the RNA Clean-Up and Concentration kit (Norgen Biotek Corp., Thorold, ON, Canada) using $20 \mu 1$ elution buffer to collect the RNA.

RNA quality. The concentration of the isolated RNA from tissue specimens was assessed by measuring the optical density at $260 \mathrm{~nm}$ (OD260) and $280 \mathrm{~nm}$ (OD280) using a Qubit ${ }^{\circledR}$ 2.0 Fluorometer (Thermo Fisher Scientific, Waltham, MA, USA) and a NanoDrop 1000 spectrophotometer (Peqlab Biotechnologie GmbH, Erlangen, Germany), whereas the quality of the RNA purified from plasma was assessed by PCR amplification curves and efficiencies, due to the absence of ribosomal RNA. RNA purity was evaluated by the ratio of the absorbance at OD260/OD280. Analysis of RNA integrity (RIN) was conducted using the Agilent 2100 Bioanalyzer (Agilent Technologies GmbH, Waldbronn, Germany) with the RNA 6000 series II Nano LabChip analysis kit. The 2100 Bioanalyzer generates numerical RIN values. RIN is an incremental scale spanning 0-10, where increasing RIN correlates with increasing RIN value. Total RNA samples extracted from CRC and adjacent neoplasm-free mucosal tissues were of high integrity as judged by the obtained RIN values of $\geq 8.0$.

miRNA quantification by real-time (RT)- $q P C R$. Total RNA including miRNAs, from a fixed plasma volume of $1 \mathrm{ml}$ or $1 \mu \mathrm{g}$ RNA from colorectal tissues, was polyadenylated and reverse transcribed to cDNA in a final volume of $20 \mu \mathrm{l}$ using the miScript Reverse Transcription kit (Qiagen) and the 5X miScript HiSpec buffer. Prior to qPCR, cDNA was diluted by adding $200 \mu \mathrm{l}$ RNase-free water to the $20 \mu \mathrm{l}$ RT reaction. qPCR assays were performed in triplicate measurements using the miScript SYBR-Green PCR kit (Qiagen, Germany) on the Rotor-Gene Q 5-Plex HRM (Qiagen) according to the manufacturer's instructions. The miRNAs utilized in this study were purchased from Qiagen.

The amplification profile was denatured at $95^{\circ} \mathrm{C}$ for $10 \mathrm{~min}$, followed by 40 cycles of $95^{\circ} \mathrm{C}$ for $15 \mathrm{sec}$ and $60^{\circ} \mathrm{C}$ for $1 \mathrm{~min}$, in which fluorescence was obtained. After the above PCR cycling program, melting curve analyses and agarose gel electrophoresis (3.0\%) on the amplicons were conducted to validate the specificity of the expected PCR amplicon. Raw cycle threshold $(\mathrm{Ct})$ values, defined as the number of cycles required for the fluorescent signal to cross the threshold in an RT-qPCR experiment, were calculated using the Rotor-Gene ${ }^{\circledR} \mathrm{Q}$ software 2.1 (Qiagen), and implementing automatic baseline settings and a threshold of 0.1 . The $\Delta \mathrm{Ct}$ was then calculated by subtracting the $\mathrm{Ct}$ values of the control [housekeeping (HK)] gene from the $\mathrm{Ct}$ values of the gene of interest. $\Delta \Delta \mathrm{Ct}$ was then calculated by
Table II. Clinicopathological characteristics of CRC patients.

\begin{tabular}{|c|c|}
\hline Variable & Frequency, $n=20$ \\
\hline \multicolumn{2}{|l|}{ Gender } \\
\hline Male & 9 \\
\hline Female & 11 \\
\hline \multicolumn{2}{|l|}{ Age at diagnosis } \\
\hline Mean \pm standard deviation & $61 \pm 10.6$ \\
\hline Median range & $61(26-84)$ \\
\hline \multicolumn{2}{|l|}{ TNM stage } \\
\hline I & 5 \\
\hline II & 3 \\
\hline III & 7 \\
\hline IV & 5 \\
\hline \multicolumn{2}{|l|}{ Nodal stage } \\
\hline Positive & 12 \\
\hline Negative & 8 \\
\hline \multicolumn{2}{|l|}{ T stage } \\
\hline $\mathrm{T} 1$ & 3 \\
\hline $\mathrm{T} 2$ & 4 \\
\hline T3 & 9 \\
\hline $\mathrm{T} 4$ & 4 \\
\hline \multicolumn{2}{|l|}{ Tumor location } \\
\hline Rectum & 7 \\
\hline Distal colon & 5 \\
\hline Proximal colon & 8 \\
\hline \multicolumn{2}{|l|}{ Histology } \\
\hline Adenocarcinoma & 16 \\
\hline Mucous adenocarcinoma & 2 \\
\hline Signet ring cell & 2 \\
\hline
\end{tabular}

CRC, colorectal cancer; TNM, tumor-node-metastasis.

subtracting $\Delta \mathrm{Ct}$ of the appropriate controls (plasma, miR-191; tissues, RNUB-6) from the $\Delta \mathrm{Ct}$ of the CRC plasma or tissue sample. The expression level of each miRNA gene was represented by fold change, which was calculated using the equation $2^{-\Delta \Delta C t}$. The efficiency of each miRNA assay was determined by constructing a standard curve using a series of total RNA dilutions. Assays exhibited good linearity $\left(\mathrm{R}^{2}>0.96\right)$ across the obtained $\mathrm{Ct}$ values and the log of the initial total RNA quantity of each dilution (data not shown).

Statistical analysis. Data were presented as mean \pm standard deviation. The Mann-Whitney U test was employed to evaluate the differential expression level of miRNAs between CRC patients and healthy controls using SPSS Data Analysis Software version 19 (SPSS, Inc., Chicago, IL, USA).

\section{Results and Discussion}

Clinicopathological characteristics of CRC patients. Inclusion criteria for the $20 \mathrm{CRC}$ patients and 20 healthy individuals (plasma control group) are detailed in Table I. The age of 
the participants was within the range of $\geq 18$ and $\leq 80$ years. Clinicopathological parameters of the 20 participants (9 men and 11 women) recruited in the study are shown in Table II. The mean age of the subjects was 61 years $( \pm 10.6$ standard deviation). None of the participants exhibited any evidence of other disease complications. In addition, 5 participants $(25 \%)$ had stage I CRC, 3 (15\%) had stage II, 7 (25\%) had stage III, while the remaining $5(35 \%)$ were diagnosed with stage IV of the disease (Table II). In terms of tumor location, 7 patients had tumors which were localized to the rectum, 5 to the distal colon and 8 to the proximal colon. Histologic examination revealed that the diagnosed CRC tumors were of the adenocarcinoma type: 16 adenocarcinoma, 2 mucous adenocarcinoma and 2 signet ring cell (Table II).

qPCR analyses of mature miRNAs. Mounting evidence suggests miRNAs function in carcinogenesis as oncogenes or tumor suppressors $(8,19,27)$. Thus, it was fundamentally important to identify CRC-related miRNA signatures by comprehensive quantitative techniques such as qPCR to broaden our understanding of their functional roles in CRC biology and pathogenesis. In this context, we selected four mature miRNAs genes, i.e., $m i R-145, m i R-195, m i R-29$ and $m i R-92$, to profile their expression levels in the plasma and tissue samples of CRC patients in relation to healthy normal specimens. Previously, the most frequently used method for the quantification of miRNAs was Northern blotting. Alsmost a decade ago, several assays including cDNA arrays, modified invader and flow cytometry were introduced for the quantitative determination of miRNAs (18,32-34). However, these assays often suffer from a serious limitation of low sensitivity due to the fact that they lack a miRNA amplification step (13). Thus, being more sensitive and RT-qPCR technology was employed to overcome the relatively low sensitivity issues of these assays (35). Traditionally, miRNA discovery workflows using global profiling are firstly conducted with either cDNA microarrays or deep sequencing (next generation sequencing). Subsequently, the RT-qPCR assay is employed as the method of choice to evaluate the diagnostic potential on a panel of selected and defined miRNAs of interest (36).

Determination of the most invariantly-expressed housekeeping miRNA gene in plasma and tissues. A critical prerequisite for any RT-qPCR assay to robustly profile circulating miRNA species in body fluids including plasma is the ability to isolate and accurately measure those miRNAs under study (30). In order to be able to accurately profile the expression of miRNA biomarkers in CRC plasma samples in relation to normal controls we first identified the most invariantly-expressed miRNA gene to utilize as a reference (HK) gene for RT-qPCR. Thus, we examined the expression of eight different miRNA genes and their differential expression between CRC and cancer-free plasma samples which was calculated by subtracting their obtained $\mathrm{Ct}$ values $\left(\Delta \mathrm{Ct}=\mathrm{Ct}^{\text {tumor }}-\mathrm{Ct}^{\mathrm{control}}\right)$. The results shown in Fig. 1 indicated that the least variable gene among the studied miRNA genes is miR-191 with a $\Delta \mathrm{Ct}$ value of only 1.7. Therefore, it was employed as a reliable HK gene for fold change calculations. Previous reports have recommended using $m i R-16, m i R-223$ or let-7a as normalizers for RT-qPCR data as they maintain a high and constantly

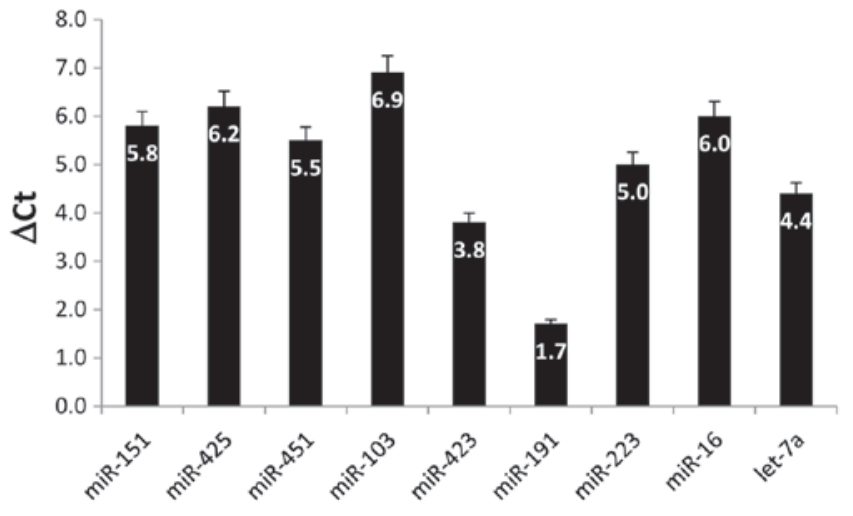

Figure 1. Identification of the most invariantly-expressed housekeeping gene in plasma samples. Cycle threshold $(\mathrm{Ct})$ values of each gene in plasma colorectal cancer samples was subtracted from $\mathrm{Ct}$ value in control plasma to obtain the $\Delta \mathrm{Ct}$ value

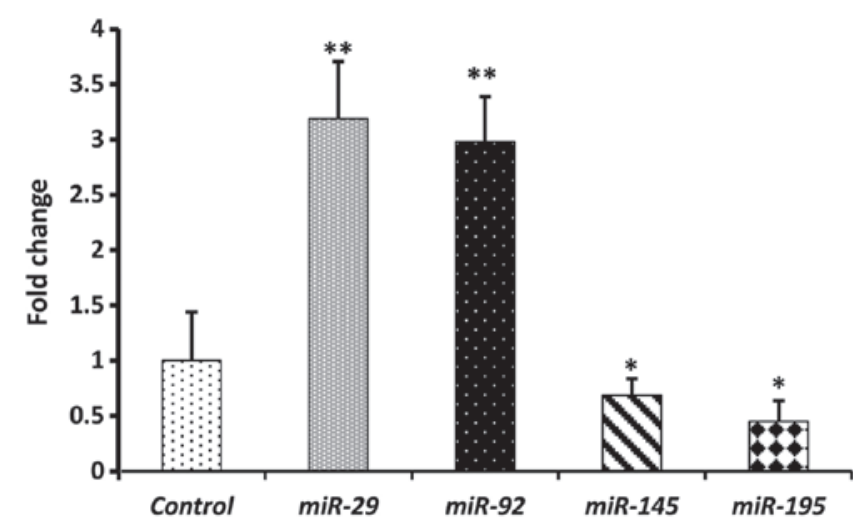

Figure 2. Fold change of $m i R-29, m i R-92, m i R-145$ and $m i R-195$ in colorectal cancer plasma in relation to neoplasm-free plasma controls. Bars show the fold change presented as mean \pm standard deviation. Experiments were conducted in triplicate $\left({ }^{*} \mathrm{P}<0.05,{ }^{* *} \mathrm{P}<0.01\right)$.

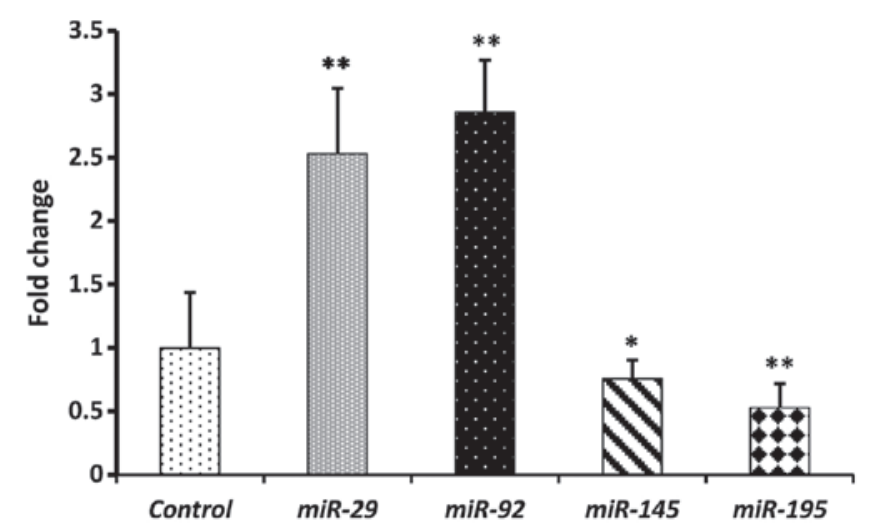

Figure 3. Fold change of $m i R-29, m i R-92, m i R-145$ and $m i R-195$ in colorectal cancer tissues in relation to adjacent neoplasm-free mucsal tissue controls. Bars show the fold change presented as mean \pm standard deviation. Experiments were conducted in triplicate $\left({ }^{*} \mathrm{P}<0.05,{ }^{* *} \mathrm{P}<0.01\right)$.

expressed level of expression in plasma/serum samples (37). However, based on our obtained results the abovementioned candidate normalizer miRNAs exhibited the most variable $\Delta \mathrm{Ct}$ values among the 9 genes examined (Fig. 1) and were therefore disregarded as HK genes in miRNA gene expression 
A

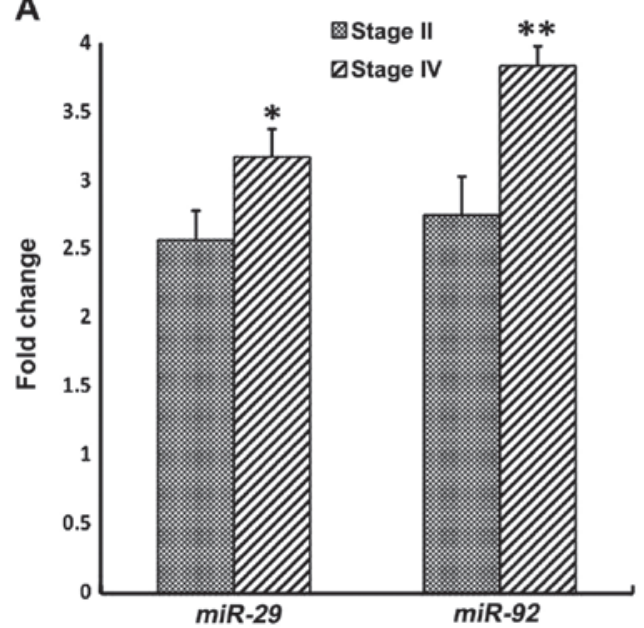

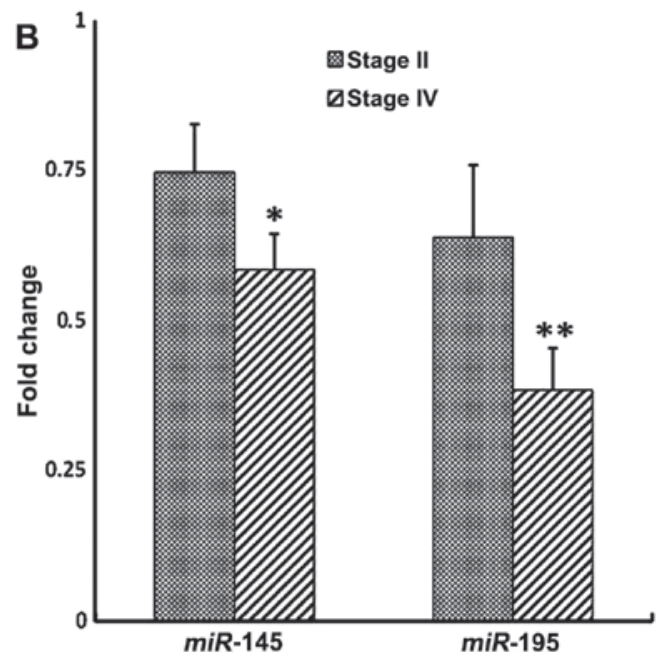

Figure 4. Fold change of $m i R-29, m i R-92, m i R-145$ and $m i R-195$ in colorectal cancer (CRC) plasma at different clinical stages. Expression levels of the four genes varied in different clinical stages. Bars show the fold change represented as mean \pm standard deviation in the plasma from 20 CRC patients versus non-neoplastic plasma controls. All experiments were conducted in triplicate $\left({ }^{*} \mathrm{P}<0.05,{ }^{* *} \mathrm{P}<0.01\right)$.

profiling in plasma. Nevertheless, more empirical validations remain to be systematically conducted in order for a consensus on robust and accurate normalization controls to be identified. As for colorectal tissues, we established RNU6B (a small nucleolar RNA gene) as an ideal internal control HK gene, as it exhibited a consistent, stable and high expression across all the tested tissue samples

Results of qPCR profiling of 20 clinical CRC plasma samples showed that the expression levels of circulating miR-29 and miR-92 were significantly higher $(\mathrm{P}<0.01)$ than in the age-matched normal plasma, with mean fold-change values of (3.2) and (2.9), respectively (Fig. 2). We then investigated the expression levels of $m i R-145$ and $m i R-195$. The mean expression levels of $m i R-145$ and $m i R-195$ were significantly lower $(\mathrm{P}<0.05)$ in $\mathrm{CRC}$ plasma than in the healthy control plasma, with means of 0.69 and 0.45 , respectively (Fig. 2). In a paired-study design employing RT-qPCR, statistically significant $(\mathrm{P}<0.01)$ increases in $m i R-29(2.5)$ and $m i R$-92 (2.6) were observed in the $20 \mathrm{CRC}$ tissue samples compared with adjacent non-cancerous colorectal mucosa (Fig. 3). By contrast, miR-145 (0.75) and miR-195 (0.53) exhibited statistically significant $(\mathrm{P}<0.05)$ decreases in their mean expression levels in CRC tissue samples in relation to normal tissues (Fig. 3). Taken together, our data clearly reflect similar trends in the expression levels of the four miRNAs in CRC tissues and plasma, as well as the positive correlation between tissue and circulating miRNAs. Moreover, the obtained results are in strong agreement with previous reports on the expression level of the four miRNAs under investigation in CRC tissues and plasma $(15,22,25-28)$, thereby confirming their potential as diagnostic biomarkers.

The ideal biomarker should possess a number of essential criteria including non-invasiveness, specificity, reliability in indicating the presence of disease prior to the manifestation of any clinical symptoms, and more importantly sensitivity to changes in the pathology (disease progression or therapeutic response) (38). Therefore, we examined whether there is an association between the aberrant expression of these circulating miRNAs genes in the plasma and CRC clinical stages (Fig. 4). Distinct stage-dependent changes in the expression level of the four miRNA gene profiles were observed between stages II and IV plasma of CRC patients relative to control plasma (Fig. 4). This observation clearly indicates that the four miRNAs under study exhibit some dynamic changes in their levels of expression as a function of the clinical cancer stage.

The identification of circulating miRNAs in plasma/ serum has led to scientific interest. Therefore, we investigated the circulating levels of two overexpressed and two downregulated miRNAs previously identified in plasma samples of CRC patients compared to healthy individuals. Colorectal adenomas are a precursor stage of adenocarinoma. Notably, it has been previously reported that the aberrantly expressed plasma $m i R-29 a$ and $m i R-92 a$ were equally efficient in discriminating advanced adenoma patients from neoplasm-free individuals, albeit with a lesser discriminatory power than for CRC patients $(22,39)$. Similar findings have been recently described in matched CRC and normal tissue samples for miR-145 at different clinical stages, emphasizing its potential as an early diagnostic biomarker for CRC (15). Furthermore, it has been reported that $m i R-145$ acts as a powerful tumor suppressor that regulates multiple cell pathways, making it an ideal biomarker for the diagnosis of various carcinomas $(27,28)$. However, further studies with larger numbers of patients and simultaneous measurements of miRNA expression in plasma and tissue are required to clarify this issue.

There are certain limitations that need to be considered when interpreting the findings of the current study. Firstly, the sample size of this study remains critically small, particularly in the context of miRNA-based biomarker identification and validation. Secondly, numerous miRNA signatures in plasma samples are generally too low to be accurately detected and quantified by RT-qPCR, a well-known limitation of this technique. Therefore, some potentially relevant markers may not be efficiently identified. In addition, the fact that no consensus endogenous control has been established yet in circulating miRNA studies complicates its reliable investigation. Some reports have advocated the use of $m i R-16$ as an endogenous 
and reliable control because of its relative stability and abundance in plasma/serum $(22,40)$. However, other reports have challenged this suggestion by showing that $m i R-16$ exhibits an aberrantly expression level in plasma/serum which was associated with the risk of prostate cancer and lymphoma $(41,42)$. We haveinitiated a high throughput miRNome profiling strategy based on next generation sequencing technology to aid with the identification of certain novel miRNA biomarkers that are differentially expressed in CRC patients (unpublished data). Thirdly, it is not clear whether the observed mis-expression levels of the four miRNAs signatures, which were examined in the current study, are CRC-specific in a Saudi population context. Additional functional dissection is required to confirm the role of the selected miRNA signatures in CRC and to validate their potential diagnostic and prognostic value.

In conclusion, the qPCR results identified alterations of miRNA expression in CRC plasma and tissues with two downregulated miRNAs (miR-145 and $m i R-195)$, and two upregulated miRNAs ( $m i R-29$ and $m i R-92$ ), which are potential candidate biomarkers for CRC. Plasma miRNAs appear to be potentially useful biomarkers for the early detection and diagnosis of CRC. While research on plasma-based miRNA profiling remains at its infancy compared to investigations on tissue-based miRNA profiling, it holds great potential for the development of novel non-invasive blood-based CRC screening approaches. Nevertheless, the diagnostic value of the identified panel of miRNA biomarker signatures may not yet be capable of competing with the performance of other traditional non-invasive tests, such as immunochemical FOBTs (39). Additional investigations on a multi-marker blood-based test, potentially including the panel of miRNAs profiled in this study among those proposed by other study groups may constitute a promising strategy to enhance the repertoire for non-invasive cancer screening programs. A panel of plasma miRNA multi-markers assays may possess a superior sensitivity and specificity as compared with other single-marker ones for CRC screening. Therefore, patients exhibiting elevated plasma miRNAs, as in the case with $m i R-29$ and $m i R-92$ for example, may initiate more targeted and accurate clinical examinations such as colonoscopy.

\section{Acknowledgements}

This study was financially supported by the National Plan for Science, Technology and Innovation (MAARIFAH), King Abdulaziz City for Science and Technology, Kingdom of Saudi Arabia, award no. (11-MED1770-02).

\section{References}

1. Ferlay J, Soerjomataram I, Ervik M, Dikshit R, Eser S, Mathers C, Rebelo M, Parkin DM, Forman D and Bray F: GLOBOCAN 2012 v1.1. Cancer Incidence and Mortality Worldwide: IARC CancerBase No. 11 (Internet). Lyon, France: International Agency for Research on Cancer; 2014. http://globocan.iarc.fr. Accessed Jan 16, 2015.

2. Saudi Cancer Registry: Cancer Incidence Report Saudi Arabia 2005. Kingdom of Saudi Arabia, Ministry of Health, Saudi Cancer Registry. http://www.scr.org.sa/reports/SCR2005.pdf. Accessed Oct 12, 2015.

3. Mosli MH and Al-Ahwal MS: Colorectal cancer in the Kingdom of Saudi Arabia: need for screening. Asian Pac J Cancer Prev 13: 3809-3813, 2012.
4. Ibrahim EM, Zeeneldin AA, El-Khodary TR, Al-Gahmi AM and Bin Sadiq BM: Past, present and future of colorectal cancer in the Kingdom of Saudi Arabia. Saudi J Gastroenterol 14: $178-182,2008$

5. O'Connell JB, Maggard MA and Ko CY: Colon cancer survival rates with the new American Joint Committee on Cancer sixth edition staging. J Natl Cancer Inst 96: 1420-1425, 2004.

6. Levin B, Lieberman DA, McFarland B, Smith RA, Brooks D, Andrews KS, Dash C, Giardiello FM, Glick S, Levin TR, et al; American Cancer Society Colorectal Cancer Advisory Group; US Multi-Society Task Force; American College of Radiology Colon Cancer Committee: Screening and surveillance for the early detection of colorectal cancer and adenomatous polyps, 2008: a joint guideline from the American Cancer Society, the US Multi-Society Task Force on Colorectal Cancer, and the American College of Radiology. CA Cancer J Clin 58: 130-160, 2008.

7. Mandel JS: Screening for colorectal cancer. Gastroenterol Clin North Am 37: 97-115, vii, 2008.

8. Herranz $\mathrm{H}$ and Cohen SM: MicroRNAs and gene regulatory networks: managing the impact of noise in biological systems. Genes Dev 24: 1339-1344, 2010

9. Friedman RC, Farh KK, Burge CB and Bartel DP: Most mammalian mRNAs are conserved targets of microRNAs. Genome Res 19: 92-105, 2009.

10. Hannafon BN, Sebastiani P, de las Morenas A, Lu J and Rosenberg CL: Expression of microRNA and their gene targets are dysregulated in preinvasive breast cancer. Breast Cancer Res 13: R24, 2011.

11. Miko E, Czimmerer Z, Csánky E, Boros G, Buslig J, Dezso B and Scholtz B: Differentially expressed microRNAs in small cell lung cancer. Exp Lung Res 35: 646-664, 2009.

12. Akao Y, Nakagawa Y and Naoe T: MicroRNA-143 and -145 in colon cancer. DNA Cell Biol 26: 311-320, 2007.

13. Bandrés E, Cubedo E, Agirre X, Malumbres R, Zárate R, Ramirez N, Abajo A, Navarro A, Moreno I, Monzó M, et al: Identification by Real-time PCR of 13 mature microRNAs differentially expressed in colorectal cancer and non-tumoral tissues. Mol Cancer 5: 29-38, 2006.

14. Michael MZ, O' Connor SM, van Holst Pellekaan NG, Young GP and James RJ: Reduced accumulation of specific microRNAs in colorectal neoplasia. Mol Cancer Res 1: 882-891, 2003.

15. Peng J, Xie Z, Cheng L, Zhang Y, Chen J, Yu H, Li Z and Kang H: Paired design study by real-time PCR: miR-378* and miR-145 are potent early diagnostic biomarkers of human colorectal cancer. BMC Cancer 15: 158-165, 2015.

16. Schepeler T, Reinert JT, Ostenfeld MS, Christensen LL, Silahtaroglu AN, Dyrskjøt L, Wiuf C, Sørensen FJ, Kruhøffer M, Laurberg S, et al: Diagnostic and prognostic microRNAs in stage II colon cancer. Cancer Res 68: 6416-6424, 2008.

17. Schetter AJ, Leung SY, Sohn JJ, Zanetti KA, Bowman ED, Yanaihara N, Yuen ST, Chan TL, Kwong DL, Au GK, et al: MicroRNA expression profiles associated with prognosis and therapeutic outcome in colon adenocarcinoma. JAMA 299: 425-436, 2008

18. Lu J, Getz G, Miska EA, Alvarez-Saavedra E, Lamb J, Peck D, Sweet-Cordero A, Ebert BL, Mak RH, Ferrando AA, et al: MicroRNA expression profiles classify human cancers. Nature 435: 834-838, 2005.

19. Waldman SA and Terzic A: MicroRNA signatures as diagnostic and therapeutic targets. Clin Chem 54: 943-944, 2008.

20. Tsang JC and Lo YM: Circulating nucleic acids in plasma/serum. Pathology 39: 197-207, 2007.

21. Chen X, Ba Y, Ma L, Cai X, Yin Y, Wang K, Guo J, Zhang Y, Chen J, Guo X, et al: Characterization of microRNAs in serum: a novel class of biomarkers for diagnosis of cancer and other diseases. Cell Res 18: 997-1006, 2008.

22. Huang Z, Huang D, Ni S, Peng Z, Sheng W and Du X: Plasma microRNAs are promising novel biomarkers for early detection of colorectal cancer. Int J Cancer 127: 118-126, 2010.

23. Mitchell PS, Parkin RK, Kroh EM, Fritz BR, Wyman SK, Pogosova-Agadjanyan EL, Peterson A, Noteboom J, O'Briant KC, Allen A, et al: Circulating microRNAs as stable blood-based markers for cancer detection. Proc Natl Acad Sci USA 105: 10513-10518, 2008.

24. Weber JA, Baxter DH, Zhang S, Huang DY, Huang KH, Lee MJ, Galas DJ and Wang K: The microRNA spectrum in 12 body fluids. Clin Chem 56: 1733-1741, 2010.

25. Liu L, Chen L, Xu Y, Li R and Du X: microRNA-195 promotes apoptosis and suppresses tumorigenicity of human colorectal cancer cells. Biochem Biophys Res Commun 400: 236-240, 2010. 
26. Li X, Wang Q, Zheng Y, Lv S, Ning S, Sun J, Huang T, Zheng Q, Ren H, Xu J, et al: Prioritizing human cancer microRNAs based on genes' functional consistency between microRNA and cancer. Nucleic Acids Res 39: e153, 2011.

27. Cui SY, Wang R and Chen LB: MicroRNA-145: A potent tumour suppressor that regulates multiple cellular pathways. J Cell Mol Med 18: 1913-1926, 2014.

28. Hou Y, Wang X, Chen Y and Mu S: MicroRNA-145 as an ideal biomaker for the diagnosis of various carcinomas. Tumour Biol 36: 2641-2649, 2015.

29. UICC: TNM Classification of Malignant Tumours. Sobin LH and Wittekind Ch (eds). 6th edition. John Wiley \& Sons, Hoboken, NJ, 2002.

30. Duttagupta R, Jiang R, Gollub J, Getts RC and Jones KW: Impact of cellular miRNAs on circulating miRNA biomarker signatures. PLoS One 6: e20769, 2011.

31. Kirschner MB, Kao SC, Edelman JJ, Armstrong NJ, Vallely MP, van Zandwijk N and Reid G: Haemolysis during sample preparation alters microRNA content of plasma. PLoS One 6: e24145, 2011.

32. Allawi HT, Dahlberg JE, Olson S, Lund E, Olson M, Ma WP, Takova T, Neri BP and Lyamichev VI: Quantitation of microRNAs using a modified Invader assay. RNA 10: 1153-1161, 2004.

33. Lim LP, Lau NC, Garrett-Engele P, Grimson A, Schelter JM, Castle J, Bartel DP, Linsley PS and Johnson JM: Microarray analysis shows that some microRNAs downregulate large numbers of target mRNAs. Nature 433: 769-773, 2005.

34. Liu CG, Calin GA, Meloon B, Gamliel N, Sevignani C, Ferracin M, Dumitru CD, Shimizu M, Zupo S, Dono M, et al: An oligonucleotide microchip for genome-wide microRNA profiling in human and mouse tissues. Proc Natl Acad Sci USA 101: 9740-9744, 2004.
35. Chen C, Ridzon DA, Broomer AJ, Zhou Z, Lee DH, Nguyen JT, Barbisin M, Xu NL, Mahuvakar VR, Andersen MR, et al: Real-time quantification of microRNAs by stem-loop RT-PCR Nucleic Acids Res 33: e179, 2005.

36. Andrews WJ, Brown ED, Dellett M, Hogg RE and Simpson DA: Rapid quantification of microRNAs in plasma using a fast real-time PCR system. Biotechniques 58: 244-252, 2015.

37. Zubakov D, Boersma AW, Choi Y, van Kuijk PF, Wiemer EA and Kayser M: MicroRNA markers for forensic body fluid identification obtained from microarray screening and quantitative RT-PCR confirmation. Int J Legal Med 124: 217-226, 2010.

38. Etheridge A, Lee I, Hood L, Galas D and Wang K: Extracellular microRNA: a new source of biomarkers. Mutat Res 717: 85-90, 2011.

39. Luo X, Stock C, Burwinkel B and Brenner H: Identification and evaluation of plasma microRNAs for early detection of colorectal cancer. PLoS One 8: e62880, 2013.

40. Song J, Bai Z, Han W, Zhang J, Meng H, Bi J, Ma X, Han S and Zhang Z: Identification of suitable reference genes for qPCR analysis of serum microRNA in gastric cancer patients. Dig Dis Sci 57: 897-904, 2012.

41. Fang C, Zhu DX, Dong HJ, Zhou ZJ, Wang YH, Liu L, Fan L, Miao KR, Liu P, Xu W, et al: Serum microRNAs are promising novel biomarkers for diffuse large B cell lymphoma. Ann Hematol 91: 553-559, 2012

42. Watahiki A, Wang Y, Morris J, Dennis K, O'Dwyer HM, Gleave M, Gout PW and Wang Y: MicroRNAs associated with metastatic prostate cancer. PLoS One 6: e24950, 2011. 